\title{
Effect of Dimensionless Number (KN and RE) on Performance Index of Concentric Circular Micro Channel
}

\author{
Pankaj Negi, Jasmeet Kalra, Maharshi Subhash
}

\begin{abstract}
Overall performance of any type of heat channel is largely depends upon Knudsen number and Reynolds number [1]. In present work the outcome of dimensionless number on heat transfer properties of micro channel heat exchanger [2]are investigated. CFD analysis of counter flowmicro channel was performed for both slip and no slip flow using Fluent as CFD code. Based on results obtain, pressure drop increases with increment in Reynolds number and Knudsen number. The effectiveness reduces with increment in Reynolds number. The comparison of thermal and hydrodynamics performance between slip and no slip flow for heat exchanger is investigated. The effectiveness increases with decreasing values of Reynolds number for counter flow. For higher effectiveness of the micro channel heat exchanger, Reynolds number should be less.
\end{abstract} Slip flow, Knudsen number, counter flow, Nusselt number

\section{INTRODUCTION}

Heat exchanger [2]is the mechanism used to exchange the thermal energy. There are several types of heat exchanger are available but due to complex design, there is a demand to design a micro channel heat exchanger.Transfer of heat is accomplished when two fluid are at different temperature. Micro channels have diameter approximately 10 to 200 micro meters.Due to smaller size, compactness, light weight, Micro channels have applications in aerospace, biomedical, Electronics industries etc.

The slip flow region corresponds to a Knudsen number between 0.001 and 0.1. Basically, a relation of mean free path to the characteristic length[1] i.e. $\mathrm{Kn}=\lambda / \mathrm{L}_{\mathrm{c}}$, Where $\lambda$ is mean free path and $\mathrm{L}_{\mathrm{c}}$ is characteristic length.

The Reynolds number [1]corresponds to inertia force and viscous force. It is a dimensionless number used to classify the fluids systems in which the effect of viscosity is important in finding the flow pattern of a fluid.

$\operatorname{Re}=\rho v d / \mu$

$D=$ Diameter of channel/passage

$V=$ Velocity

$\rho=$ Density

$\mu=$ Viscosity

In previous years researchers emphasized on different methods to improve heat transfer in different types of heat exchanger.

Revised Manuscript Received on August 10, 2019.

Pankaj Negi, Assistant Professor, Department of Mechanical Engineering, Graphic Era Hill University, Dehradun, Uttarakhand, India.

Jasmeet Kalra, Assistant Professor, Department of Mechanical Engineering, Graphic Era Hill University, Dehradun, Uttarakhand, India.

Maharshi Subhash, Associate Professor, Department of Mechanical Engineering, Graphic Era (Deemed to be) University, Dehradun, Uttarakhand, India.
Keywords: Reynolds number, Micro channel heat exchanger,

But due to high demand of micro channel in industrial application, it is necessary to develop such micro channel. Theory of micro channel heat sink for VLSI circuit was explained [3]. Experimental investigation of micro channel was given by Harpole and Eninger [4].After that manifold micro channel was numerically investigated by Copeland [5].Where manifold micro channel are more efficient than the regular micro channel heat sinks. Their study shows that same temperature variation present in much shorter distance for manifold micro channels. An optimization investigationfor reducing the temperature gradient for micro channel heat sink was performed by Bau in 1998[6]. Their results show that the minimization of temperature achieved by changing the geometry of micro channel. Numerical investigation of multi-layer micro channelhaving counter flow was performed [7]. [8] Analysed the two-phase flow patterns for circular tubes. Several flow structures characteristics were described. They classified micro channels with the help of Laplace constant and channel diameter. Numerical investigation of circular tube micro channel was performed by Stephan [9] and also found that differentiation of micro and mini channel by a hydraulic diametercould not be done everywhere. Kandlikar and Grande [10] experimentally analysed the different phase for circular or square tube. They proposed the following criteria to classify the different types of heat channels.

Micro channels dia.: $10 \mu \mathrm{m} \square$ to $\square 200 \mu \mathrm{m}$

Mini channels dia.: $200 \mu \mathrm{m} \square$ to $\square 3 \mathrm{~mm}$

Regular channels dia.: > $6 \mathrm{~mm}$

Choi et al. [11] found that continuum analysis is not able to see fluid characteristics in micro scale devices. The governing equation fails to develop the fluid pattern in micro channels. These equations need a modification by including slip and temperature risenear wall.[12] Investigation of the flow of liquid and gases in silicon micro channel. They determined that conventional studies arenot able to get accurate solution for micro channel heat exchanger.[13] Analysis for gaseous slip flow in the micro channel was completed. Result show that the continuum approach is not efficient to solve the micro channel. Rise in temp. And slip isneeded to be considered to get the appropriate solutions. Palm [14] studied the micro passages as heat exchanger. They found that the conventional concepts (continuum approach) cannot accurately predict thermo-hydraulic performance. Araki et al. [15] experimentally studied the transport of gases in micro channel and found the deficiency in heat transfer without considering velocity slip boundary conditions. Study of thermally developed flow in the circular tube [16] was

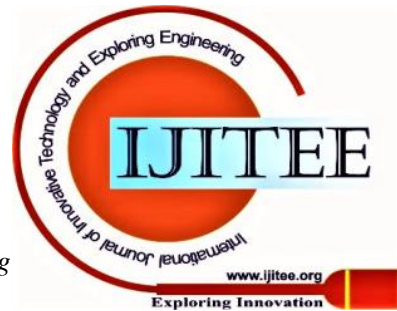


performed. The constant wall temperature was considered. The thermal performance with different Reynolds number and geometrical parameters were determined. Duan and Muzychka [17] did investigation of slip flow in annular micro channels having constant flux. The analytical methods were used. They observe that Nusselt number is reducing while growth of Knudsen number. Role of Knudsen number and radius ratio on heat transfer were determined.[18] Experimentally investigate rectangular micro channel with slip flow heat transfer. They investigated that effect of aspect ratio seriously on the pressure and heat transfer in bothtypes of flow. [19] Analyticallyshow the slip flow in rectangular passageshavingfixedtemperature at walls. Investigation of heat transfer in a rectangular design was completed [20]. The constant heat flux was taken in the problem. The flow was assumedas thermally and hydro dynamically fully developed. [21] Numerical study of the parallel flow micro channel with rectangular shape. They found that the high conductive material do not have effect on effectiveness. Khan and Yovanovich [22] did investigation of both micro and Nano channel sinks. Analysis shows pressure drop differs with variationin Knudsen number and aspect ratio of channel. Numerical investigation of the parallel-plate micro channel heat exchanger was performed [23]. The flow was considered as two dimensional, laminar having slip flow. As Knudsen number rises there is increment in slip and temperature jump. Heat transfer mechanism during slip flow was studied in cross flow micro channel [24]. Theinfluence of tube hydraulic diameter was calculated. Brandner et al. [25] investigated micro channels sink with cross flow heat devices.Comparison made for different micro flows. Result show that heat transfer significantly increase by minimisingthe diameter of the micro channel sink.[26] Two methods were proposed for the evaluation of micro channels for increasingrate of heat transfer. The first methodwasaddition of numerical and analytical data. It was carried to find the aspect ratio of geometries. Anotherway is related to genetic algorithm in collaboration with numerical solution.

Above literature explains that the micro channel heat exchangers with rectangular, annular etc. shape were investigatedbut there are limited studies of two fluids micro channel heat exchangers. So in the present work the numerical investigation of concentric circular micro channel heat exchanger with slip flow heat transfer is done.

\section{METHODOLOGY}

Modeling of problem is done using the physical and geometrical assumptions, governing equation and numerical simulation. The following assumptions are taken.

1. Slip flow (0.001 $\square \mathrm{Kn} \square 0.1)$ is assumed in the micro channel.

2. Flow is steady, incompressible, 3D and laminar.

3. Air is considered as working fluid.

4. Pressure gradient is considered in axial direction only.

5. No heat transfer to and from the channel.

6. Ends of separating wall are insulated.
Computational fluid dynamics analysis was performed using Fluent as CFD code. Continuity, momentum and energy equation are based on above assumption was solved.

\subsection{Continuity equation:}

$$
\frac{\partial u}{\partial x}+\frac{\partial v}{\partial y}+\frac{\partial w}{\partial z}=0
$$

$\mathrm{U}, \mathrm{V}$ and $\mathrm{W}$ are the velocity component in $\mathrm{X}, \mathrm{Y}$ and $\mathrm{Z}$ direction [1].

\subsection{Energy Balance Equation}

This equation is quiet used for heat channels performance evaluations. It is used to determine operating parameters for both hot and cold fluid which is flowing inside the channel. Ex-Flow rate, inlet, outlet temperatures

\section{PARAMETERS FOR HEAT EXCHANGER PERFORMANCE EVALUATION}

Following parameters are important in evaluation of heat exchanger performance specially thermal and hydraulic performance.

\subsection{Heat Transfer Rate}

Quantity of heat is transferred between two fluids [2].

$\mathrm{q}=\mathrm{m}_{\mathrm{c}} \mathrm{C}_{\mathrm{pc}}\left(\mathrm{T}_{\mathrm{c}, \text { out }}-\mathrm{T}_{\mathrm{c}, \text { in }}\right)=\mathrm{m}_{\mathrm{h}} \mathrm{C}_{\mathrm{ph}}\left(\mathrm{T}_{\mathrm{h}, \text { in }}-\mathrm{T}_{\mathrm{h}}\right.$,

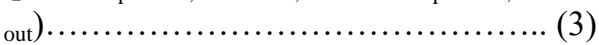

\subsection{Effectiveness}

It gives relation between actual amounts of heat transfer to the maximum possible amount of heat that can be transferred [2].

$\varepsilon=\mathrm{q}_{\text {actual }} / \mathrm{q}_{\max }$.possible

Where, $q_{\text {actual }}=m_{c} C_{p c}\left(T_{c}\right.$ out $\left.-T_{c, \text { in }}\right)=m_{h} C_{p h}\left(T_{h, \text { in }}-T_{h, \text { out }}\right)$

$\mathrm{q}_{\text {max. Possible }}=\mathrm{C}_{\min }\left(\mathrm{T}_{\mathrm{h}, \text { in }}-\mathrm{T}_{\mathrm{c}, \text { in }}\right)$

Where,

$\mathrm{T}_{\mathrm{h}, \mathrm{in}}=$ Hot Inlet

$\mathrm{T}_{\mathrm{c}, \text { in }}=$ Cold Inlet

$\mathrm{T}_{\mathrm{h}, \text { out }}=$ Hot outlet

$\mathrm{T}_{\mathrm{c}, \text { out }}=$ Cold Outlet

\subsection{Pressure Drop}

$\Delta \mathrm{P}_{\mathrm{t}}=\Delta \mathrm{P}_{\mathrm{h}}+\Delta \mathrm{P}_{\mathrm{c}}=\left(\mathrm{P}_{\mathrm{h}, \text { in }}-\mathrm{P}_{\mathrm{h}, \text { out }}\right)+\left(\mathrm{P}_{\mathrm{c}, \text { in }}-\mathrm{P}_{\mathrm{c}, \text { out }}\right)[1]$

\subsection{Performance Index}

It is defined as the ratio of heat exchanger effectiveness [2] to the total pressure drop in that heat exchanger flow.It shows the relation between thermal and hydraulic efficiency of heat devices. It is also valuable in evaluating the overall performance of heat exchanger.

$\eta=\varepsilon / \Delta \mathrm{P}_{\mathrm{t}}$ 
Where,

$\varepsilon=$ Effectiveness of channel

$\Delta \mathrm{P}_{\mathrm{t}}=$ Pressure Drop in channel

\subsection{Nusselt Number}

It is important number which is often used in heat transfer problems to find the heat transfer between two mediums [2]. It gives the relation between convective and conductive heat transfer.

$\mathrm{N}_{\mathrm{u}}=\mathrm{hD}_{\mathrm{h}} / \mathrm{k}_{\mathrm{f}}$

Fourier law [2] of conductivity describes the rate of heat transfer through any medium or material is corresponds to temperature gradient. Heat flux is mentioned by $\mathrm{q}_{\mathrm{i}}$ in below equation. Where $\boldsymbol{\delta} \mathrm{T}$ is temperature difference and $\boldsymbol{\delta} \mathrm{x}$ is length.

Following are the geometrical parameters were considered during design:

Outer tube diameter, $\mathrm{D}_{\mathrm{o}}=200 \mu \mathrm{m}=0.2 \mathrm{~mm}$ and Inner tube diameter, $\mathrm{D}_{\mathrm{i}}=100 \mu \mathrm{m}=0.1 \mathrm{~mm}$, Length of tube, $\mathrm{L}=10 \mathrm{~mm}$, wall thickness, $\mathrm{t}=5 \mu \mathrm{m}=0.005 \mathrm{~mm}$

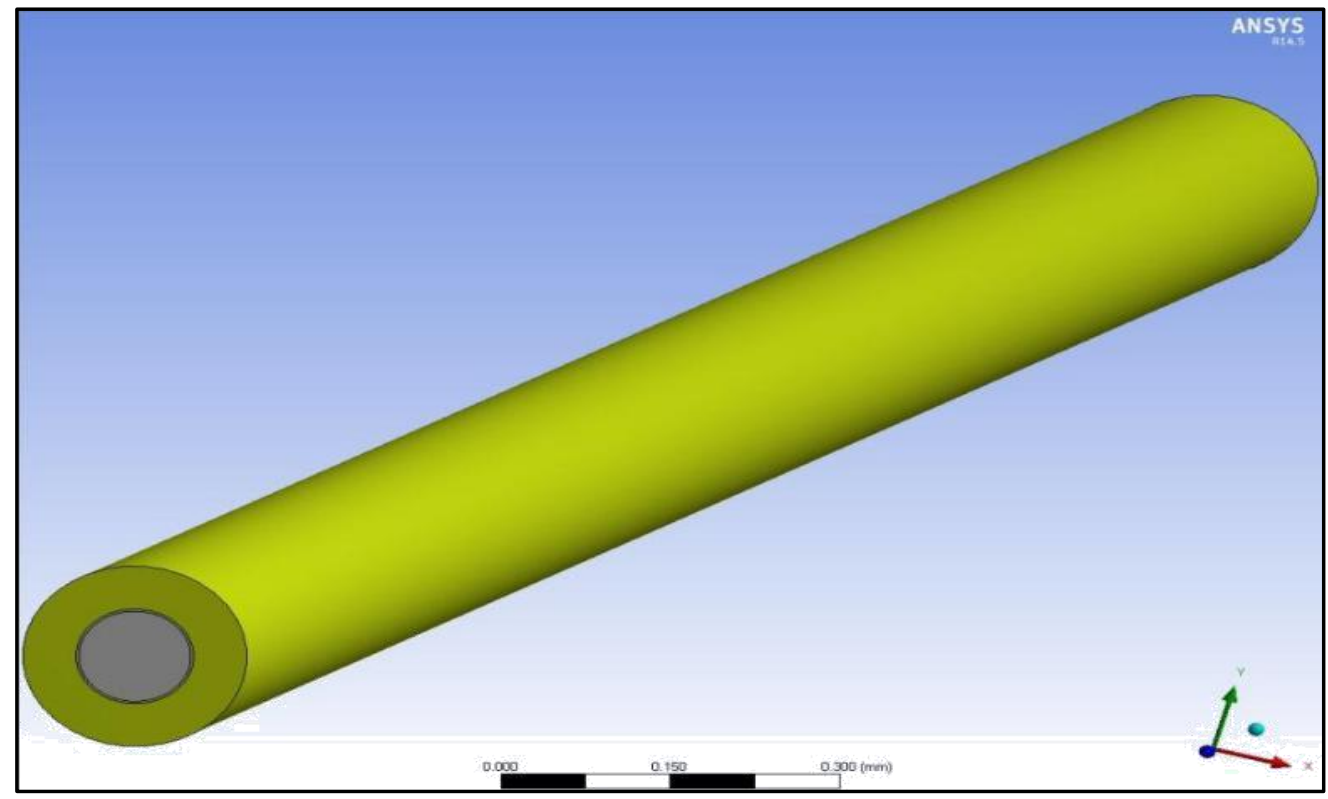

Fig. 1: Concentric circular micro channel

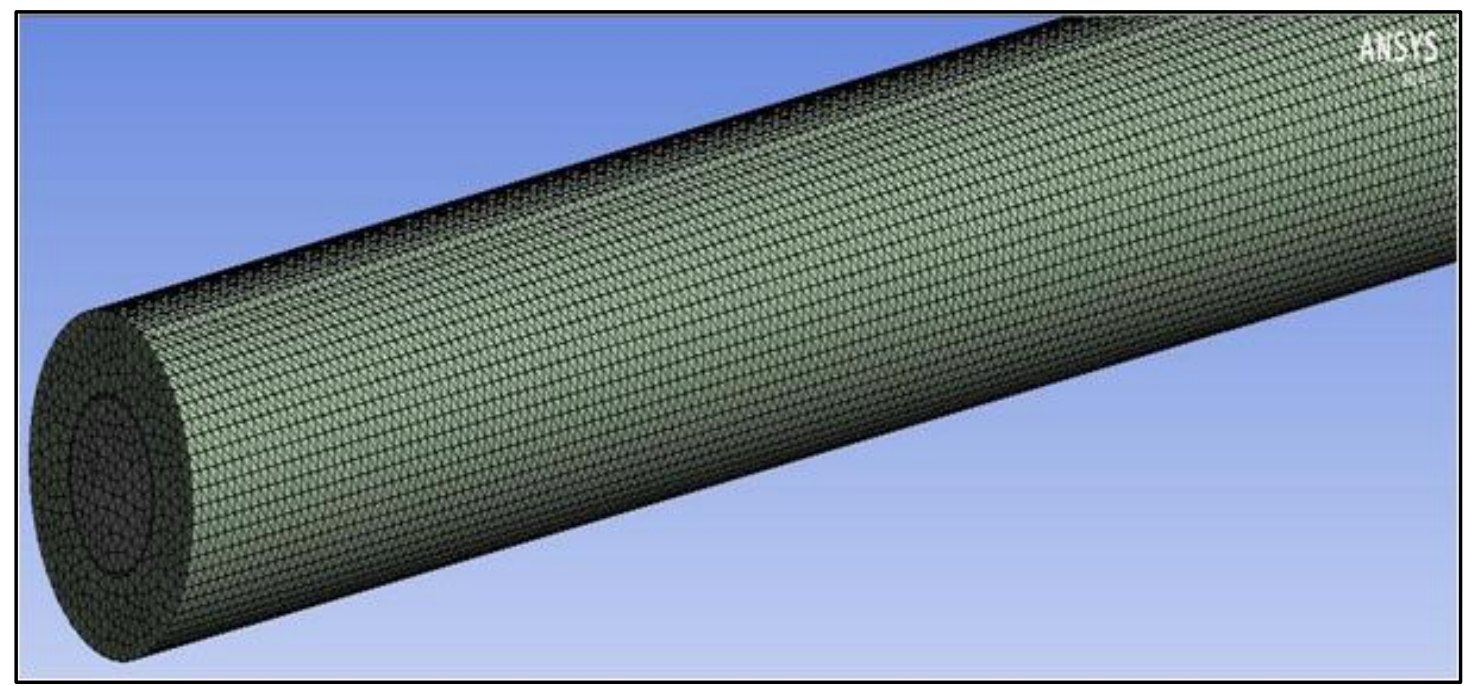

Fig. 2: Meshing of Domain

$$
q_{i}=-k \frac{\partial T}{\partial x_{i}}
$$

\section{CFD ANALYSIS OF MICRO CHANNEL HEAT EXCHANGER}

FLUENT as CFD code is used to simulate the domain. Temperature, velocity and pressure fields are identified for fluid domain. Through CFD investigation we can evaluate heat exchanger performance in the terms of heat transfer rate, effectiveness etc. K- $\varepsilon$ Turbulence [1] model is used to study the fluid domain. 
Effect of Dimensionless Number (KN and RE) on Performance Index of Concentric Circular Micro Channel

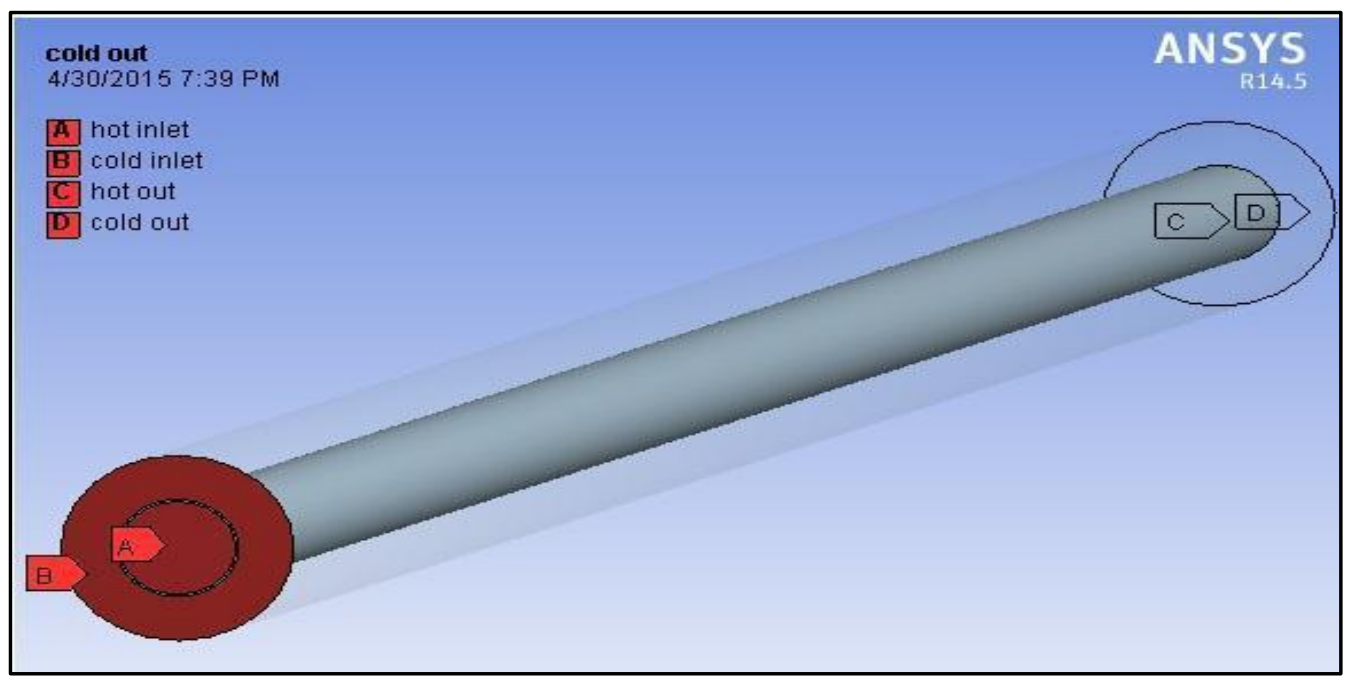

Fig. 3: Inlet and Outlet boundaries for micro channel

\section{RESULT AND DISCUSSION}

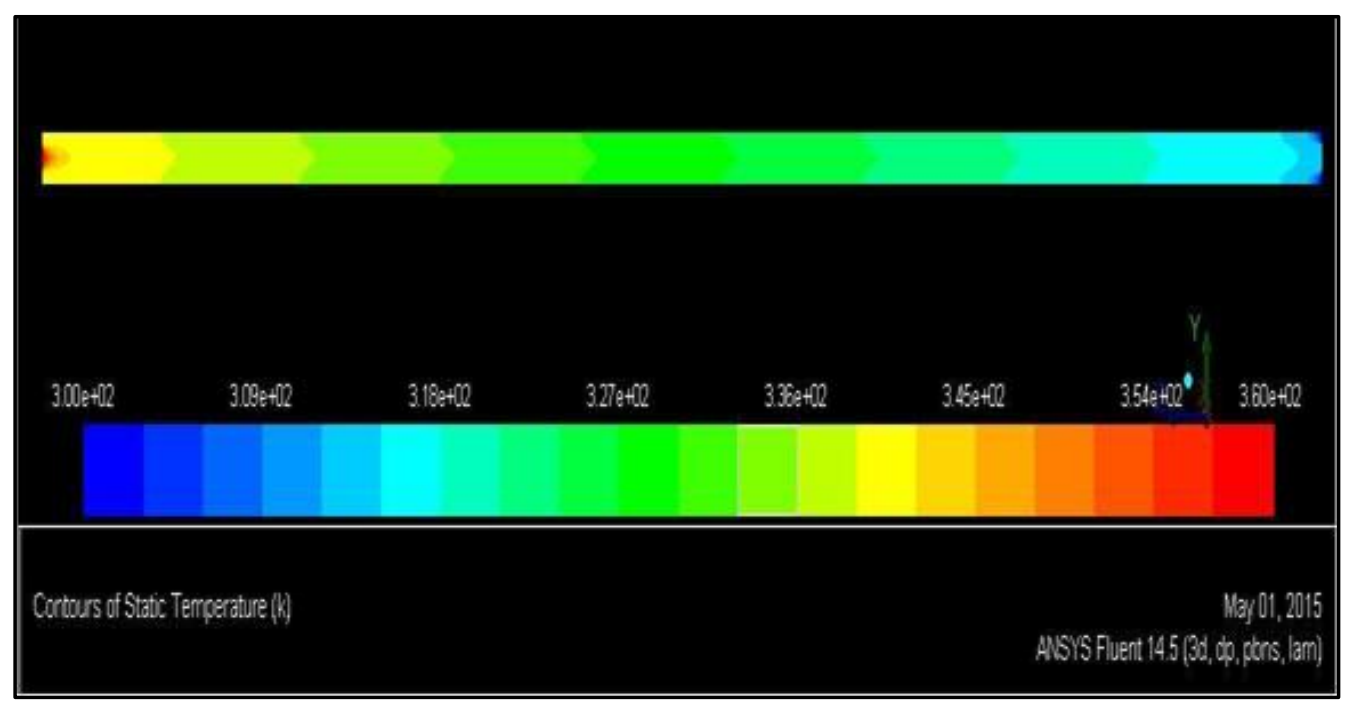

Fig. 4: Temperature distribution Contour

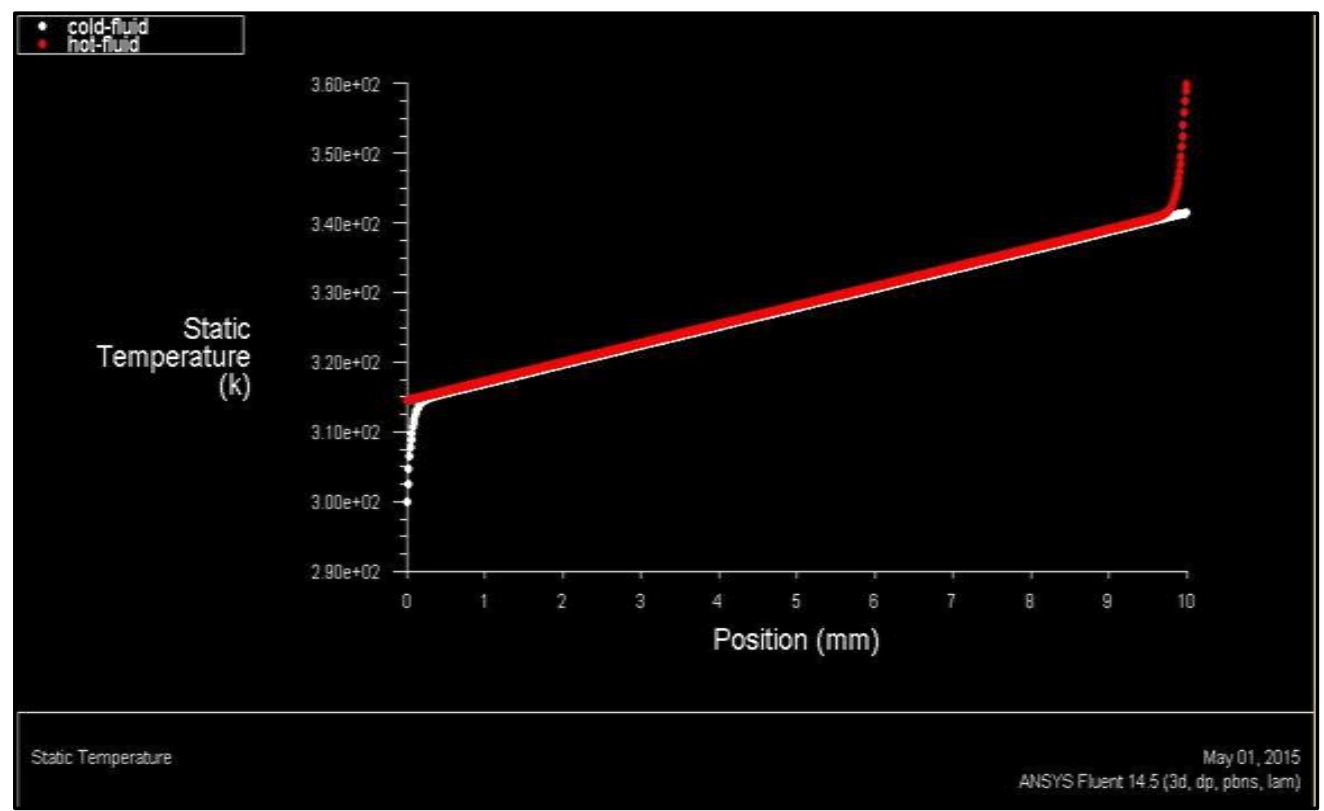

Fig. 5: Temperature plot for micro channel

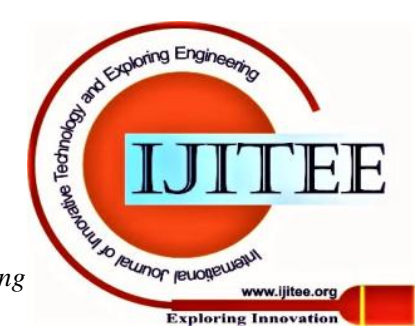




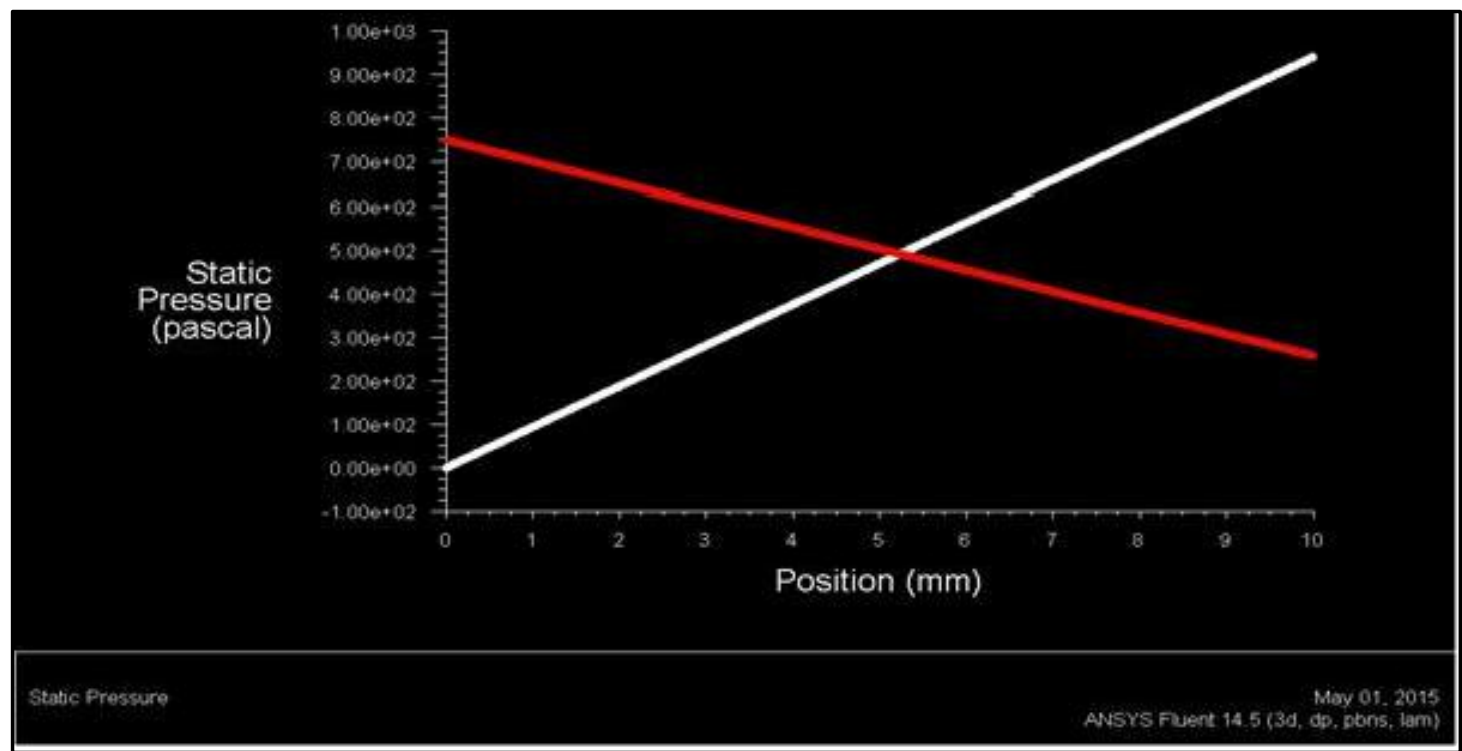

Fig. 6: Pressure distribution through channel

Effectiveness is measured by comparing slip and no slip flow parameters. This comparison is done for counter flow. Temperatures for hot inlet and cold inlet are $360 \mathrm{~K}$ and $300 \mathrm{~K}$ respectively. The mass flow rates for $\mathrm{Re}=10$ and 20 are $1.578 \mathrm{e}-08 \mathrm{~kg} / \mathrm{s}$ and $7.894 \mathrm{e}-08$ respectively. And specific heat is $1006.43 \mathrm{~J} / \mathrm{kg}-\mathrm{K}$ for both configurations.

Table 1: Comparison between Slip and No Slip Flow at different Reynolds Number

\begin{tabular}{|c|l|l|l|}
\hline $\begin{array}{c}\text { Reynolds } \\
\text { Number }\end{array}$ & \multicolumn{1}{|c|}{ Parameter } & \multicolumn{2}{c|}{ Fluid(Air) and Solid(Al) } \\
\hline \multirow{4}{*}{10} & & \multicolumn{1}{|c|}{ Slip Flow } & \multicolumn{1}{c|}{ No Slip Flow } \\
\cline { 2 - 4 } & Outlet Temp.(Hot) & $311.8 \mathrm{~K}$ & $316 \mathrm{~K}$ \\
\cline { 2 - 4 } & Outlet Temp.(Cold) & $346 \mathrm{~K}$ & $342 \mathrm{~K}$ \\
\cline { 2 - 4 } & Effectiveness & 0.78 & 0.70 \\
\hline \multirow{3}{*}{50} & Outlet Temp.(Hot) & $315.2 \mathrm{~K}$ & $318.1 \mathrm{~K}$ \\
\cline { 2 - 4 } & Outlet Temp.(Cold) & $345 \mathrm{~K}$ & $342 \mathrm{~K}$ \\
\cline { 2 - 4 } & Effectiveness & 0.76 & 0.69 \\
\hline
\end{tabular}

In the comparison we have taken aluminium (Al) and copper $(\mathrm{Cu})$ for the channel materials. Counter flow is considered at Reynolds number 10 and 50. The comparison shows that slip flow has more effectiveness than the no-slip flow in each case. High velocity slip and less temperature jump is assumed for present work.Thermal contact resistance is less in case of high velocity slip. Hence slip flow has more effectiveness than the no-slip.

\subsection{Variation in Effectiveness with Reynolds Number}

Table 2: Variation of effectiveness at different Reynolds Number at $\mathrm{Kn}=0.01$

\begin{tabular}{|c|c|c|c|c|c|}
\hline Flow type & \multicolumn{5}{|c|}{ Effectiveness, $\varepsilon$} \\
\hline Reynolds Number & $\mathbf{1 0}$ & $\mathbf{2 0}$ & $\mathbf{3 0}$ & $\mathbf{4 0}$ & $\mathbf{5 0}$ \\
\hline Counter flow & 0.79 & 0.773 & 0.768 & 0.759 & 0.75 \\
\hline
\end{tabular}

Channel with aluminium material has more effectiveness than the copper. The reason of high effectiveness is low thermal conductivity ratio $\left(\mathrm{k}_{\mathrm{r}}\right)$ of aluminium channel. This is ratio of conductivity of solid and fluid. Due to less thermal conductivity ratio the axial conduction is also less in the aluminium channel. The optimum value of thermal conductivity ratio is 90 for counter flow in the micro channel. As value increases for thermal conductivity after certain value the effectiveness decreases. 


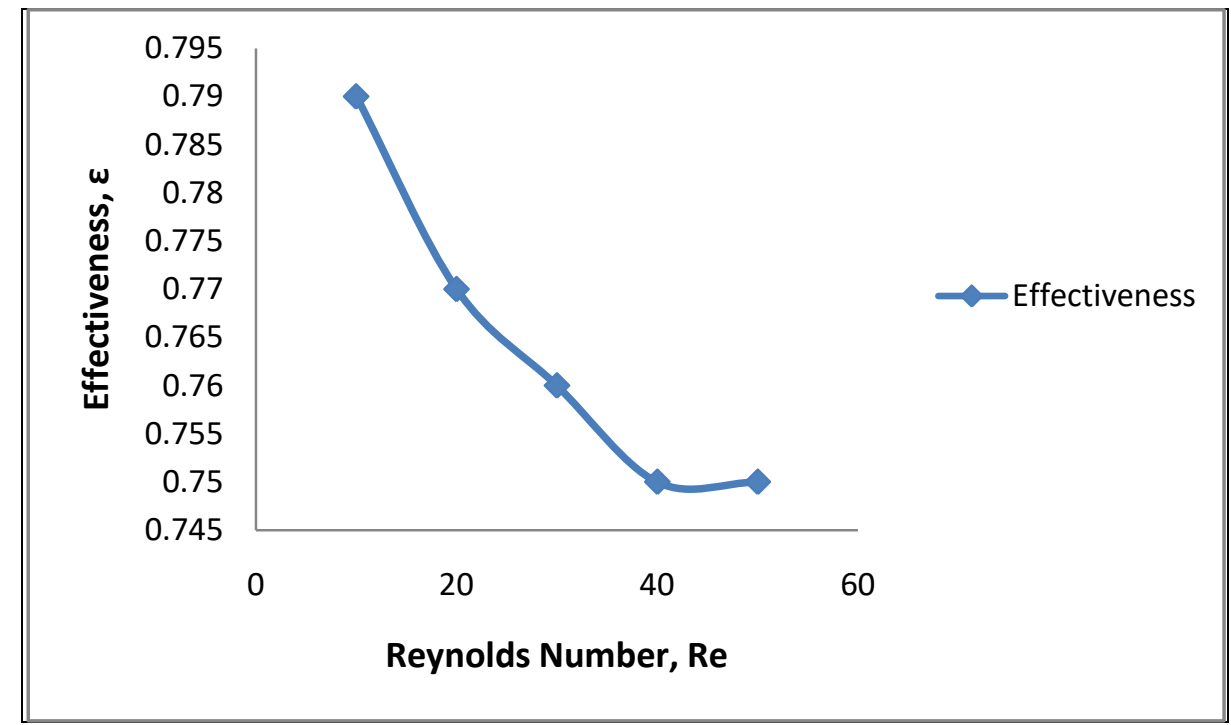

Fig. 7: Variation of Effectiveness

Table 2 shows that, the effectiveness increment while reducing values of Reynolds number for counter flow. For higher effectiveness of the micro channel Reynolds number should less.

\subsection{Change in Pressure drop with Reynolds Number}

Table 3: Pressure drop distribution with different Reynolds Number through axial distance at $\mathrm{Kn}=0.01$

\begin{tabular}{|c|c|c|c|c|c|}
\hline \multirow{2}{*}{$\begin{array}{l}\text { Axial Distance } \\
(\mathbf{m m})\end{array}$} & & \multicolumn{4}{|c|}{ Pressure Drop (Pa) } \\
\hline & Reynolds No & 10 & 20 & 30 & 40 \\
\hline 1 & & 95 & 186 & 295 & 430 \\
\hline 2 & & 186 & 345 & 615 & 760 \\
\hline 3 & & 280 & 572 & 872 & 1170 \\
\hline 4 & & 376 & 745 & 1155 & 1500 \\
\hline 5 & & 475 & 940 & 1385 & 1920 \\
\hline 6 & & 565 & 1135 & 1690 & 2230 \\
\hline 7 & & 660 & 1320 & 1965 & 2665 \\
\hline 8 & & 752 & 1510 & 2260 & 3000 \\
\hline 9 & & 845 & 1675 & 2615 & 3415 \\
\hline 10 & & 940 & 1860 & 2890 & 3770 \\
\hline
\end{tabular}

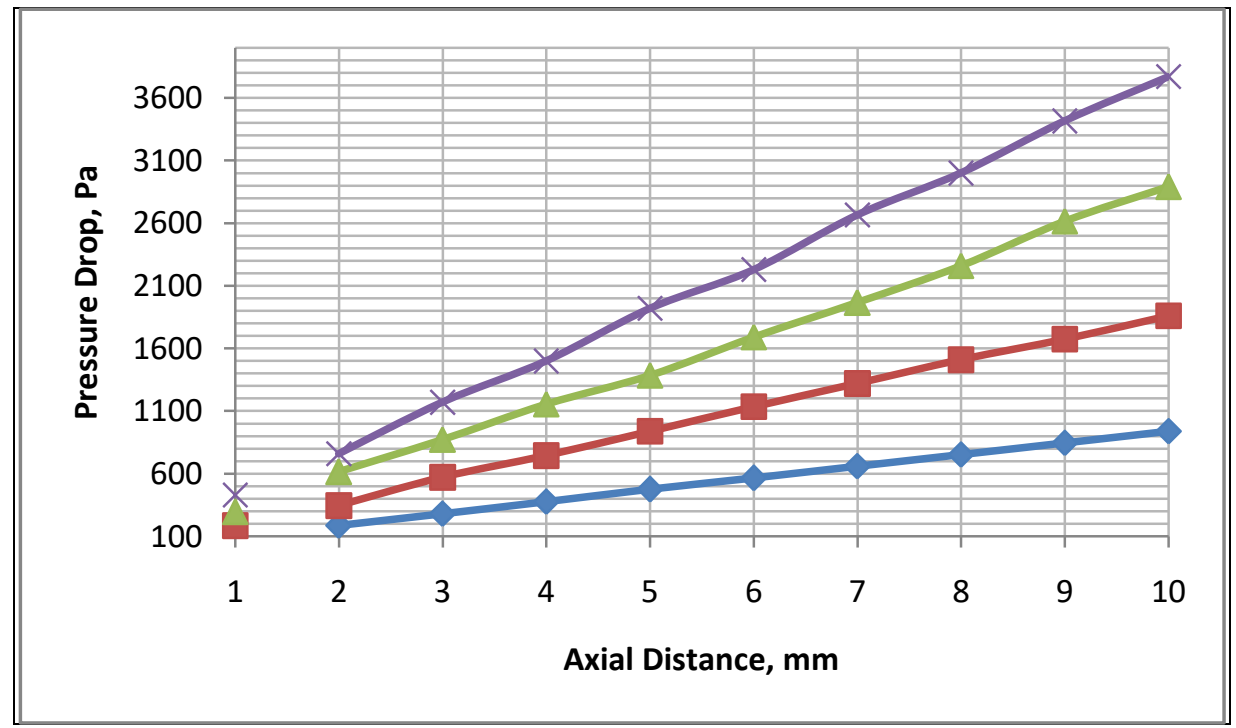

Fig. 8: Variation in Pressure Drop

Fig. 8 shows that pressure drop is more for higher value of Reynolds number. $\mathrm{Re}=10$ has minimum pressure drop and $\mathrm{Re}=40$ has maximum pressure drop. 
Higher Reynolds number means high inlet velocity, because Reynolds numbers depend on the inlet velocity. Due to higher value of shear stress the pressure drop is more. Pressure drop is directly link to the pumping power of the heat exchanger. High pressure drop would raise the pumping power of the device and ultimately increases the overall cost of the operation.

\subsection{Variation in Pressure Drop for different Knudsen Number through axial distance}

Table 4: Pressure Drop variation for different Knudsen Number

\begin{tabular}{|c|c|c|c|c|c|}
\hline \multirow{2}{*}{$\begin{array}{c}\text { Axial Distance } \\
(\mathbf{m m})\end{array}$} & \multicolumn{5}{|c|}{ Pressure Drop (Pa) } \\
\hline & $K n=0.001$ & $K n=0.005$ & $\mathrm{Kn}=\mathbf{0 . 0 1}$ & $K n=0.05$ & $\mathrm{Kn}=\mathbf{0 . 1}$ \\
\hline 1 & 20 & 35 & 95 & 271 & 740 \\
\hline 2 & 45 & 65 & 185 & 535 & 1420 \\
\hline 3 & 65 & 105 & 280 & 845 & 1985 \\
\hline 4 & 95 & 130 & 376 & 1105 & 2610 \\
\hline 5 & 125 & 155 & 468 & 1450 & 3215 \\
\hline 6 & 140 & 175 & 565 & 1755 & 3750 \\
\hline 7 & 155 & 205 & 665 & 2052 & 4250 \\
\hline 8 & 170 & 235 & 760 & 2345 & 4755 \\
\hline 9 & 185 & 285 & 845 & 2605 & 5110 \\
\hline 10 & 210 & 315 & 940 & 2790 & 5430 \\
\hline
\end{tabular}

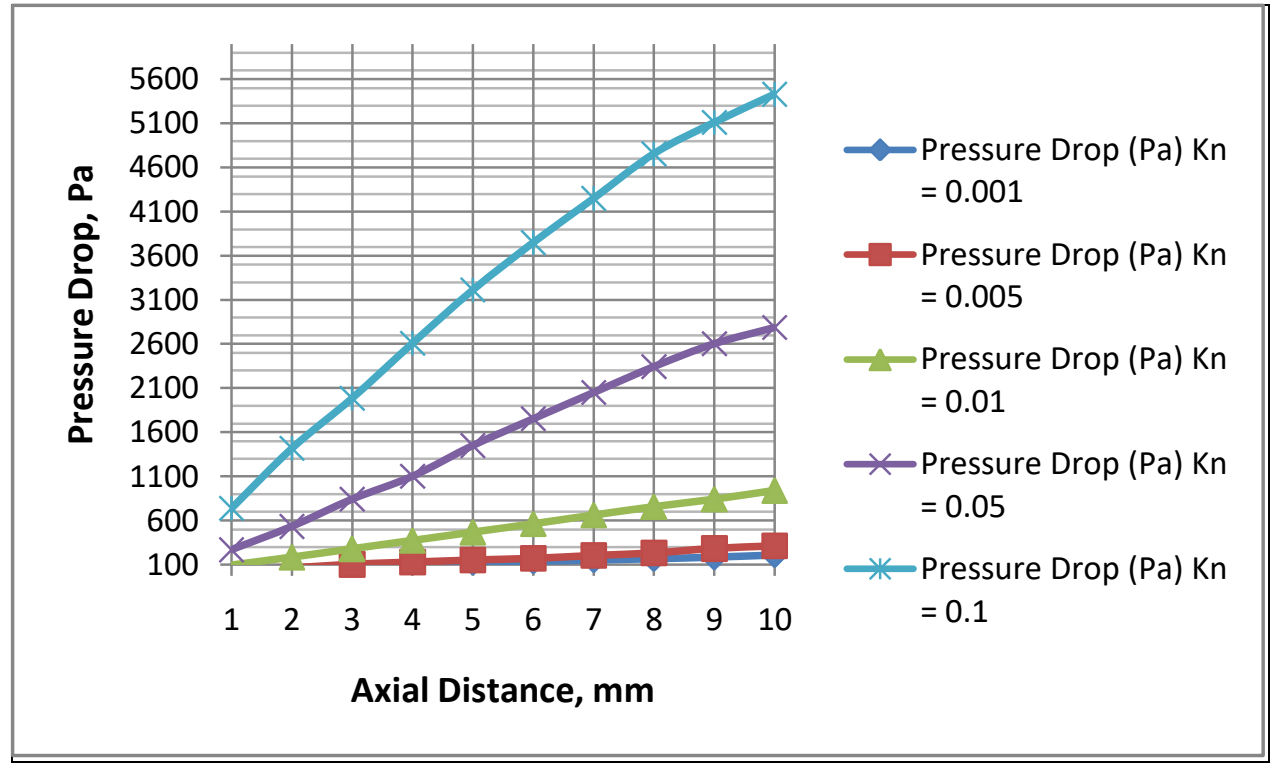

Fig. 9: Variation in Pressure Drop with Knudsen Number

Table 4 show the change of pressure drop through axial distance of channel for different Knudsen number. This is taken for cold channel of counter flow with $\mathrm{Re}=10$. From the Table 3.6 and Fig. 3.16 it isassumed that drop in pressure is increasing with higher values of Knudsen number. $\mathrm{Kn}=0.001$ has minimum pressure drop and $\mathrm{Kn}=$ 0.1 has maximum pressure drop.

\subsection{Pressure drop distribution with Reynolds Number}

Table 5: Variation of total pressure drop for counter flow with different $\operatorname{Re}$ at $\mathrm{Kn}=0.01$

\begin{tabular}{|c|c|c|c|c|c|}
\hline \multirow{2}{*}{ Reynolds } & \multicolumn{2}{|c|}{ Hot fluid } & \multicolumn{2}{c|}{ Cold fluid } & \multirow{2}{*}{ Total pressure } \\
\cline { 2 - 5 } & $\mathbf{P}_{\text {hi }}(\mathbf{P a})$ & $\mathbf{P}_{\text {ho }}(\mathbf{P a})$ & $\mathbf{P}_{\mathrm{ci}}(\mathbf{P a})$ & $\mathbf{P}_{\text {co }}(\mathbf{P a})$ & Drop, P (Pa) \\
\hline $\operatorname{Re}=10$ & 948 & 47 & 615 & 142 & 1374 \\
\hline
\end{tabular}


Effect of Dimensionless Number (KN and RE) on Performance Index of Concentric Circular Micro Channel

\begin{tabular}{|c|c|c|c|c|c|}
\hline $\mathrm{Re}=20$ & 1899.5 & 94.7 & 1329.6 & 379.7 & 2754.7 \\
\hline $\mathrm{Re}=30$ & 2855.9 & 142.45 & 1999.02 & 570.8 & 4141.67 \\
\hline $\mathrm{Re}=40$ & 3816.5 & 190.5 & 2671.4 & 762.9 & 5534.5 \\
\hline $\mathrm{Re}=50$ & 4783.9 & 247.4 & 3321.4 & 930.9 & 6927 \\
\hline
\end{tabular}

From the above table it is clear that total pressure drop is increasing with higher values of Reynolds number. $\mathrm{Re}=10$ has minimum total pressure drop and $\mathrm{Re}=50$ has maximum total pressure drop.
Hence it is found thattotal drop in pressure for a heat exchanger unit is risingas Reynolds number rises. It happens due to the higher value of shear stress at higher Reynolds number.

\subsection{Friction Factor vs Reynolds Number}

Table 6: Variation of friction factor for counter flow with different $\operatorname{Re}$ at $\mathrm{Kn}=\mathbf{0 . 0 1}$

\begin{tabular}{|c|c|c|}
\hline Reynolds number, Re & Total pressure drop, P (Pa) & Friction factor, fr \\
\hline 10 & 1374 & 1043.361892 \\
\hline 20 & 2754.7 & 526.9703328 \\
\hline 30 & 4141.67 & 352.1153923 \\
\hline 40 & 5534.5 & 264.6765053 \\
\hline 50 & 6927 & 212.0142904 \\
\hline
\end{tabular}

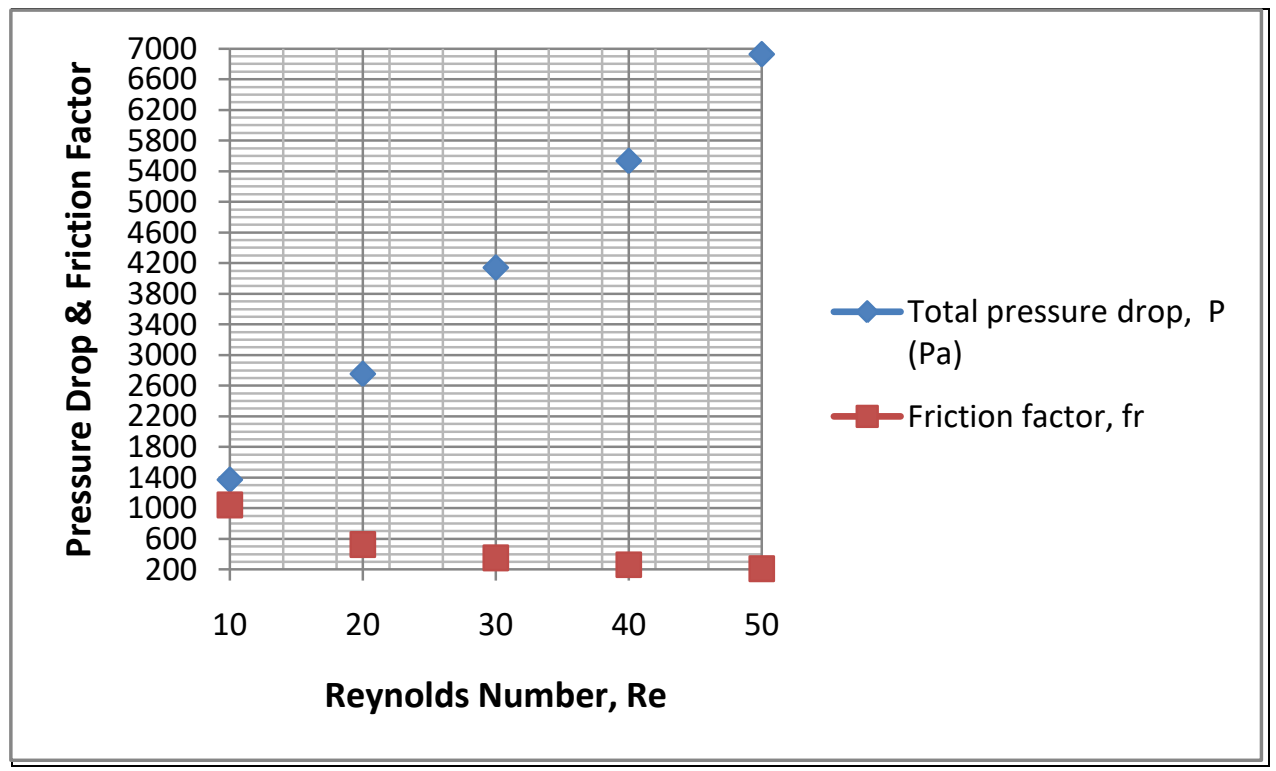

Fig. 10: Change in Friction Factor by changing Reynolds Number

From the above graph it can be observe that friction factor is decreasing with increased values of Reynolds number. Re
$=10$ has maximum friction factor and $\operatorname{Re}=50$ has minimum friction factor. 
International Journal of Innovative Technology and Exploring Engineering (IJITEE) ISSN: 2278-3075, Volume-8 Issue-10S2, August 2019

5.6 Effect of channel height on fully developed velocity

Table 7: Fully developed velocity Variation for counter flow with channel height at $\mathbf{R e}=10$

\begin{tabular}{|c|c|c|c|c|c|c|}
\hline \multirow{2}{*}{$\begin{array}{l}\text { Channel } \\
\text { height, } \\
\text { y (mm) }\end{array}$} & \multicolumn{5}{|c|}{ Slip flow velocity $(\mathrm{m} / \mathrm{s})$} & \multirow{2}{*}{$\begin{array}{l}\text { Channel } \\
\text { height, } \\
\text { y (mm) }\end{array}$} \\
\hline & $K n=0.001$ & $K n=0.005$ & $\mathrm{Kn}=\mathbf{0 . 0 1}$ & $\mathrm{Kn}=\mathbf{0 . 0 5}$ & $K n=0.1$ & \\
\hline 0 & 0 & 0.16 & 0.31 & 0.4 & 0.58 & 0.1 \\
\hline 0.005 & 0.75 & 1.4 & 1.44 & 1.51 & 1.6 & 0.095 \\
\hline 0.01 & 1.46 & 1.62 & 1.6 & 1.7 & 1.81 & 0.09 \\
\hline 0.015 & 1.65 & 1.68 & 1.77 & 1.85 & 1.9 & 0.85 \\
\hline 0.02 & 2.27 & 2.43 & 1.8 & 1.9 & 1.95 & 0.08 \\
\hline 0.025 & 2.6 & 2.5 & 2.1 & 2 & 1.99 & 0.075 \\
\hline 0.03 & 2.8 & 2.76 & 2.4 & 2.2 & 2.1 & 0.07 \\
\hline 0.035 & 2.9 & 2.88 & 2.49 & 2.25 & 2.15 & 0.065 \\
\hline 0.04 & 3.1 & 3.08 & 2.6 & 2.38 & 2.2 & 0.06 \\
\hline 0.045 & 3.2 & 3.11 & 2.71 & 2.45 & 2.25 & 0.055 \\
\hline 0.05 & 3.3 & 3.25 & 2.8 & 2.55 & 2.3 & 0.05 \\
\hline
\end{tabular}

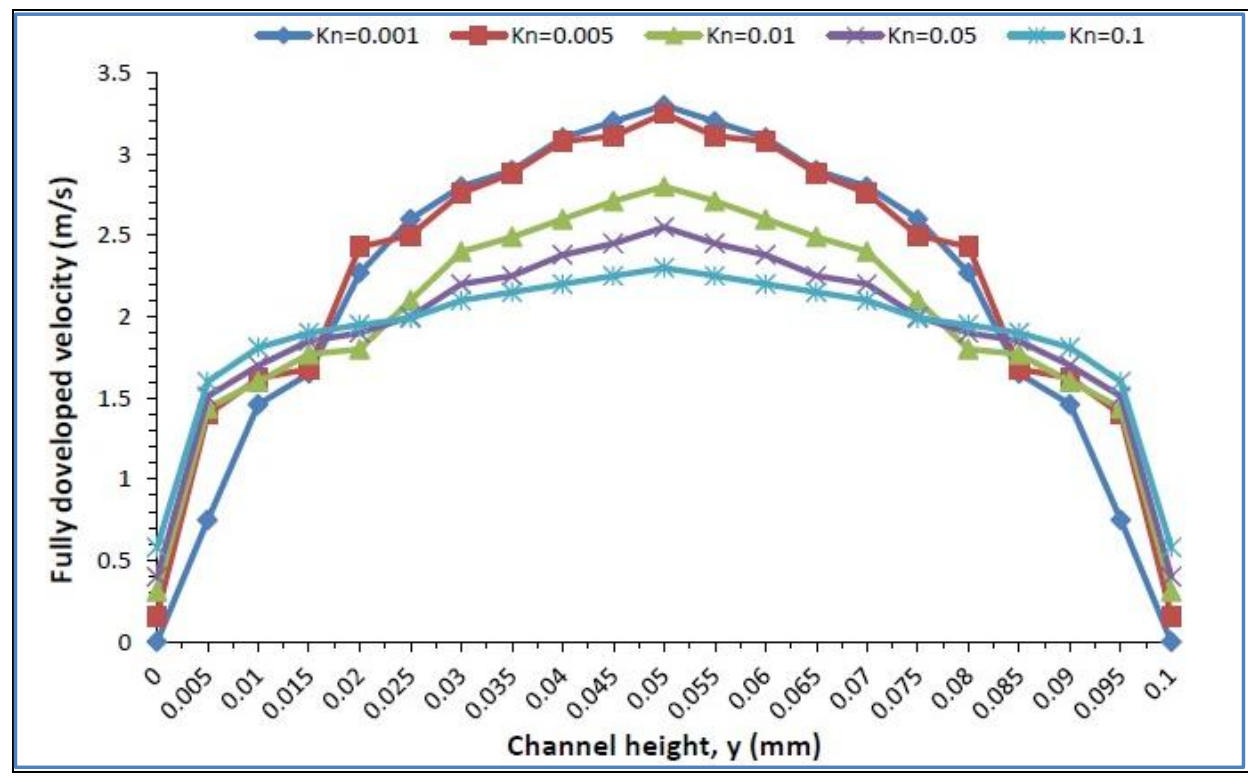

Fig. 11: Variation in Velocity with channel height 
Table 7 show the distribution of velocity with different channel height for differentKnudsen number. Observation is taken for hot channel of counter flow with $\mathrm{Re}=10$. Knudsen number defined here from 0.001 to 0.1 .

From Table 7 it can be observe that with increment in Knudsen number, velocity near the wall is increasing. This happens due to the slip region increases with increment in Knudsen number. $\mathrm{Kn}=0.001$ has zero slip velocity and $\mathrm{Kn}$ $=0.1$ has slip velocity of 0.58 near the wall.

\subsection{Heat Transfer Rate variation with Reynolds Number}

Table 8: Change in heat transfer rate for counter flow, $\mathrm{Re}$ at $\mathrm{Kn}=0.01$

\begin{tabular}{|c|c|c|}
\hline Reynolds & Maximum possible rate of heat transfer & Actual rate of heat transfer \\
\hline number & $\mathbf{q}_{\max }(\mathbf{W})$ & $\mathbf{q}_{\text {actual }(\mathrm{W})}$ \\
\hline $\mathrm{Re}=10$ & 0.952 & 0.75208 \\
\hline $\mathrm{Re}=20$ & 1.91 & 1.47643 \\
\hline $\operatorname{Re}=30$ & 2.85 & 2.1888 \\
\hline $\operatorname{Re}=40$ & 3.812 & 2.893308 \\
\hline $\operatorname{Re}=50$ & 4.76 & 3.57 \\
\hline
\end{tabular}

From table 8 this isobserve that as rise in Reynolds number the rate of heat transfer is increasing. Variation is linear for both situations.As Reynolds number increases the difference is also increasing. Minimum heat transfer
At the centre of channel velocity is reducing with increased value of Knudsen number. $\mathrm{Kn}=0.1$ has core velocity of 2.3 $\mathrm{m} / \mathrm{s}$ is minimum and $\mathrm{Kn}=0.001$ has core velocity of $3.3 \mathrm{~m} / \mathrm{s}$ is maximum. Low value of core velocity means minimum Reynolds number, which is required for maximum effectiveness. So the higher value of Knudsen number has more effectiveness.

5.8 Change inheat transfer coefficient through axial distance of channel

Table 9: Local overall heat transfer coefficient through axial distance

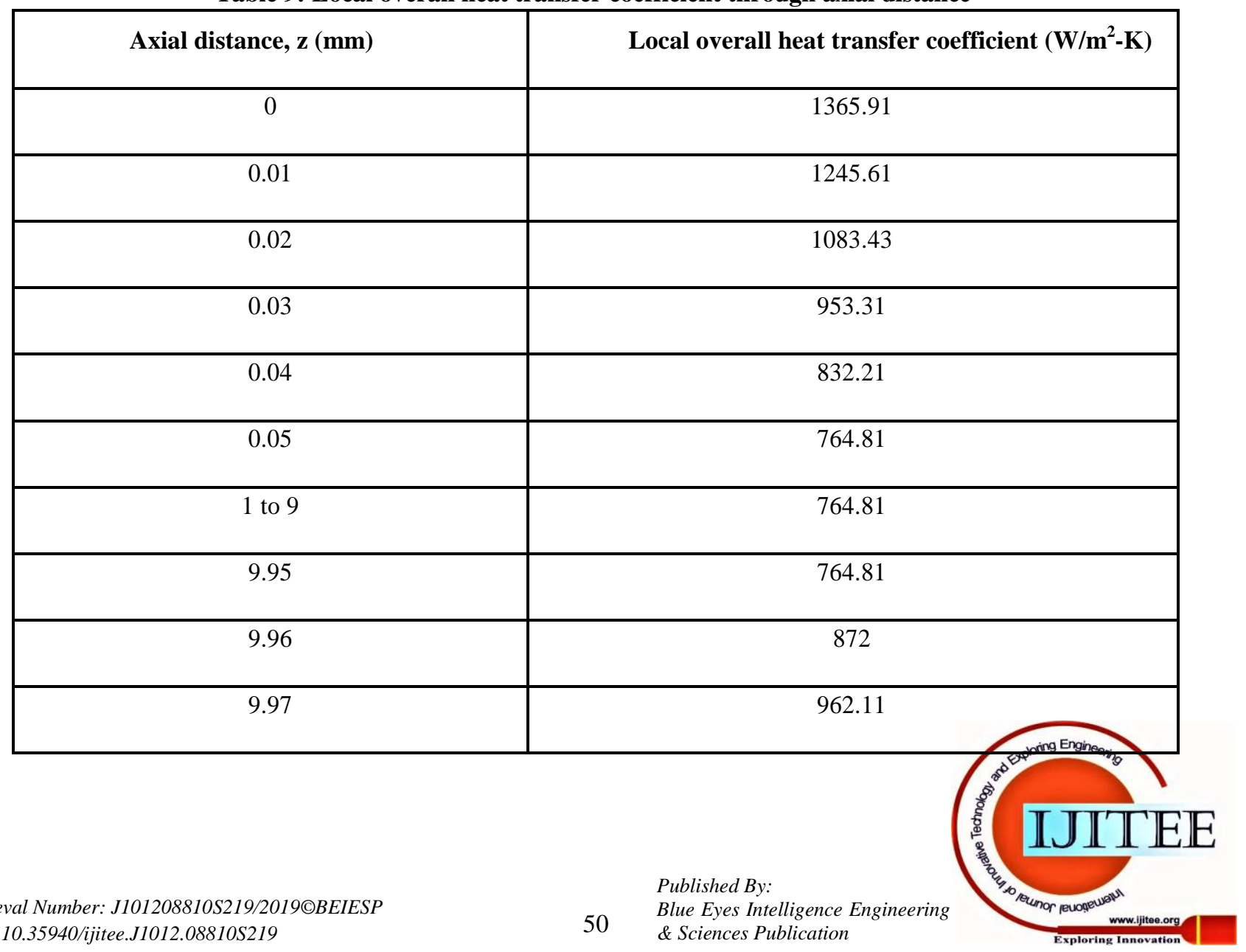

difference and maximum heat transfer difference occurs at $\operatorname{Re}=10$ and $\operatorname{Re}=50$. Reynolds number should be less to get the minimum heat transfer difference. This minimum heat transfer difference leads to high effectiveness. 


\begin{tabular}{|c|c|}
\hline 9.98 & 1057.41 \\
\hline 9.99 & 1152.3 \\
\hline 10 & 1241.3 \\
\hline
\end{tabular}

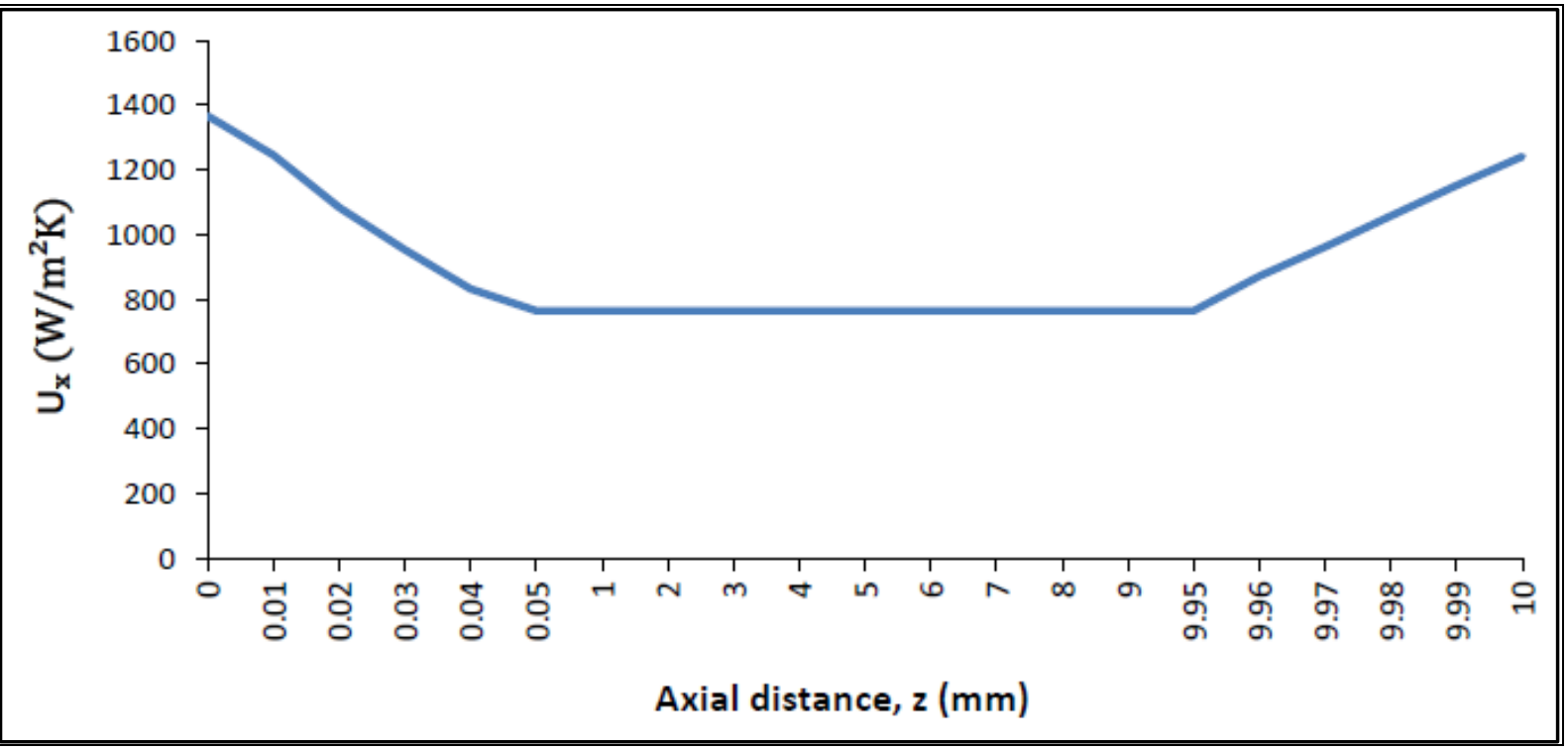

Fig. 12 Local overall heat transfer coefficient Vs axial distance

Table 9 shows that local overall heat transfer coefficient is varying. Its value is not constant. Heat transfer coefficient is more at inlet of both fluid (hot and cold) compare than remaining distance of channel.

\subsection{Effect on local Nusselt number through axial distance}

Table 10: Local Nusselt number for counter flow through axial distance at $\operatorname{Re}=10$

\begin{tabular}{|c|c|c|c|c|c|}
\hline \multirow{2}{*}{$\begin{array}{c}\text { Axial distance, } \\
\mathbf{z}(\mathbf{m m})\end{array}$} & \multicolumn{5}{|c|}{ Local Nusselt number, Nu } \\
\cline { 2 - 6 } & Kn = 0.001 & Kn = 0.005 & Kn = 0.01 & Kn = 0.05 & Kn = 0.1 \\
\hline 0 & 4.36 & 7.1 & 11.86 & 13.5 & 16.56 \\
\hline 0.01 & 3.9 & 5.55 & 9.8 & 11.2 & 14.32 \\
\hline 0.02 & 3.49 & 4.6 & 7.72 & 9.4 & 11.4 \\
\hline 0.03 & 3.41 & 3.8 & 6.1 & 7.32 & 9.32 \\
\hline 0.04 & 3.39 & 3.6 & 4.66 & 5.5 & 7.11 \\
\hline 0.05 & 3.32 & 3.4 & 3.63 & 4.1 & 4.32 \\
\hline 1 & 3.32 & 3.4 & 3.63 & 4.1 & 4.32 \\
\hline 9 & 3.32 & 3.4 & 3.63 & 4.1 & 4.32 \\
\hline 10 & 3.32 & 3.4 & 3.63 & 4.1 & 4.32 \\
\hline
\end{tabular}




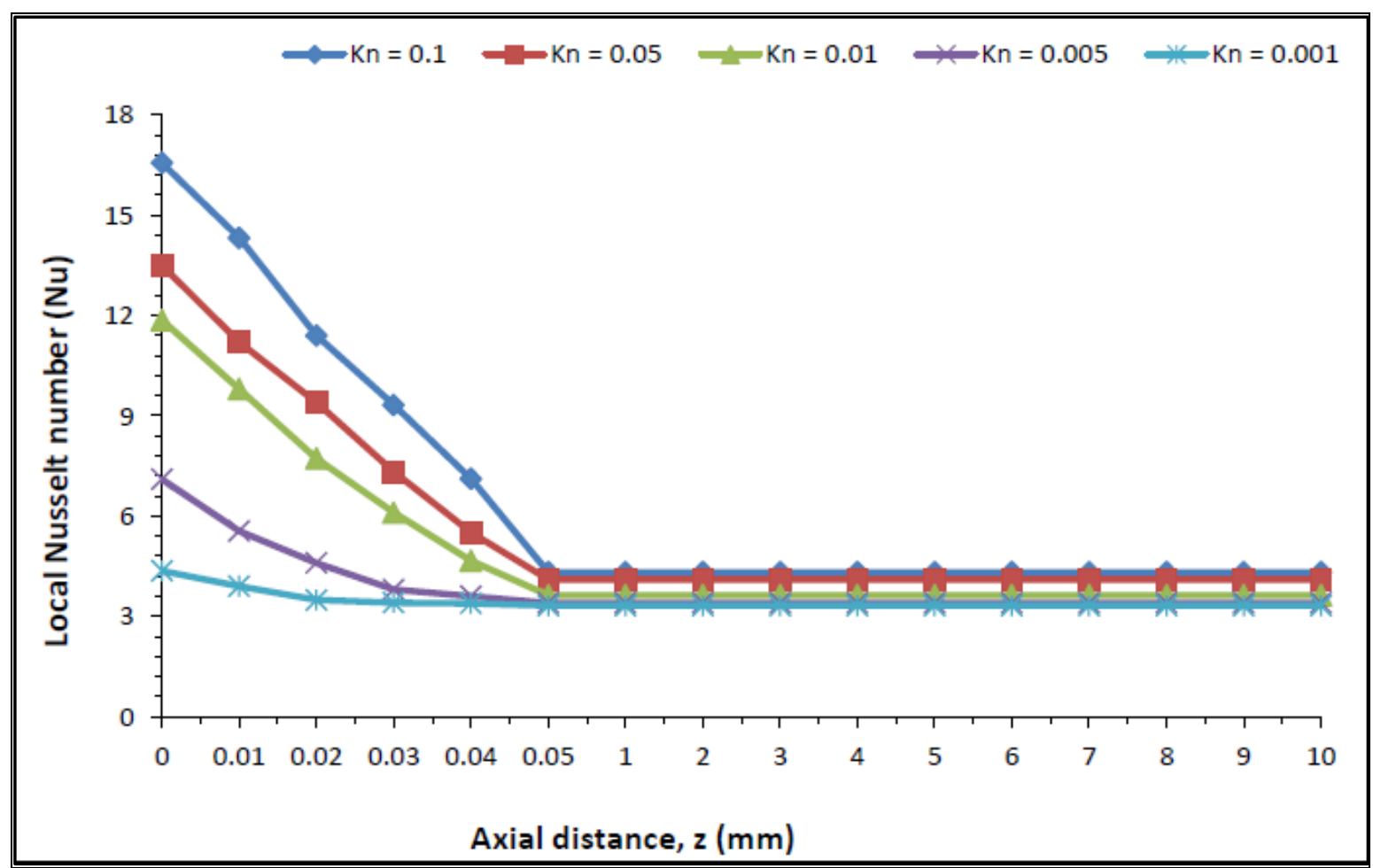

Fig. 13: Nusselt number Vs axial distance

Table 10 show the data of change in local Nusselt number with axial distance of cannel for different Knudsen number. This distribution is taken for hot fluid in counter flow with $\mathrm{Re}=10$. The range of Knudsen number are taken are 0.001 , $0.005,0.01,0.05$ and 0.1 .

From the Table 10, observation is that while increment in Knudsen number the Nusselt number is increasing. $\mathrm{Kn}=0.1$ has maximum Nusselt number and $\mathrm{Kn}=0.001$ has minimum Nusselt number. The reason of increment in Nusselt number is domination of velocity slip at the higher digits of Knudsen number.

Nusselt number value is decreasing till the flow becomes fully developed. In the fully developed flow profilethe Nusselt number is become constant. This trend of varying Nusselt number is same with all Knudsen numbers.

\subsection{Performance index of micro channel with Reynolds Number}

Table 11: Variation in performance index for counter flow with $\operatorname{Re}$ at $\mathrm{Kn}=0.01$

\begin{tabular}{|c|c|c|c|c|c|}
\hline Reynolds number, Re & 10 & 20 & 30 & 40 & 50 \\
\hline Performance index & 0.000575 & 0.000281 & 0.000185 & 0.000137 & 0.000108 \\
\hline
\end{tabular}

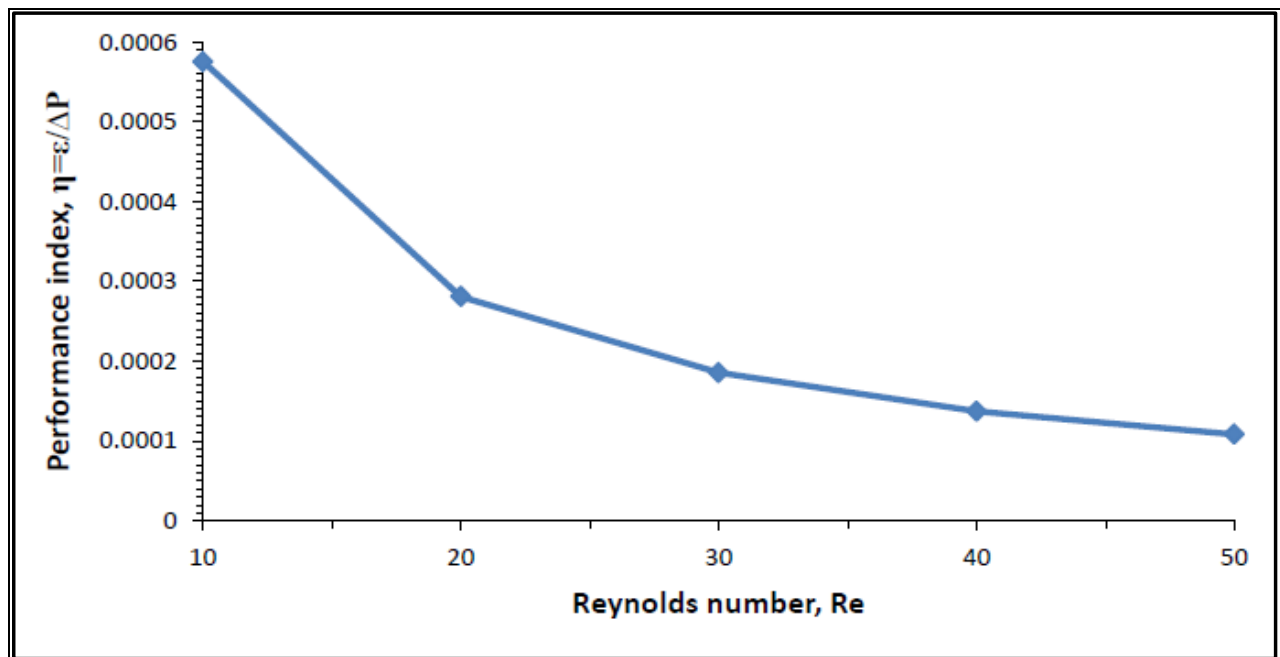

Fig. 14: Performance index Vs Reynolds Number 
Table 11 shows the change in performance index with change in Reynolds number. Performance index shows the relation between the thermal and hydrodynamic performance. Result is taken for counter flow with $\mathrm{Kn}=$ 0.01 . The different values of Reynolds number taken are 10 , 20, 30, 40 and 50. Computed data shows that as Reynolds number increases the performance index of micro channel is decreasing. At $\operatorname{Re}=10$ has highest performance index and at $\mathrm{Re}=50$ has lowest. This is because of increment in pressure drop and decreasing value of effectiveness with higher values of Reynolds number.

\section{VALIDATION OF PRESENT WORK}

To verify the present model it is necessary to validate the previous problem with present model and compare them. Validation and verification is done on the basis of comparison of numerical results.

The numerical model (FORTRAN code) presented by Ahmed et al. [27] is a micro channel used as a cooling system of electronic circuitshaving two layers of rectangular micro channels with counter flow. To check the validity of present work, numerical solution is done for [27] and comparison is made to see the differences.

The physical or geometrical assumptions are taken from Ahmed et al. [27]. Length and hydraulic diameter are two main parameters were considered which are $10 \mathrm{~mm}$ and 100 $\mu \mathrm{m}$. The boundary conditions and constant thermo-physical properties are taken for rectangular micro channel.

Fig. 2.4 gives the comparison of variation of fully developed velocity with channel height. Comparison and error percentage between Ahmed et.al. [27]And present numerical model are determined. The maximum dimensionless fully developed velocity difference between results of [27] and present work is 0.022 and maximum error is $1.67 \%$. The average difference is 0.108 and average error is $0.83 \%$. The above results are in the range of acceptance. From the verification it is observed that present numerical model is valid and reliable to simulate the microchannel heat exchanger.

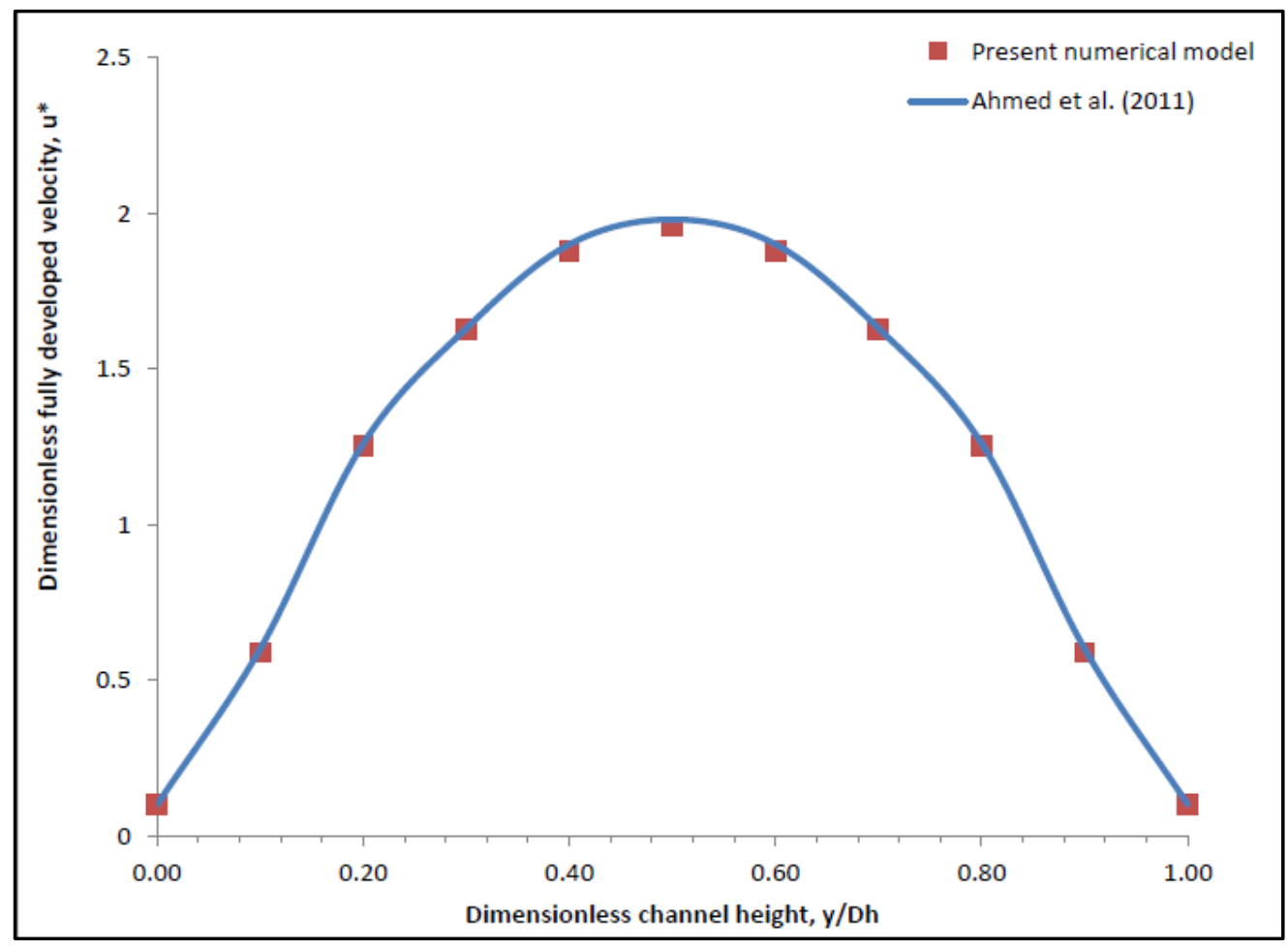

Fig. 15: Validation of Present Work

\section{CONCLUSION}

The concentric circular micro channel is analysed numerically with slip flow heat transfer. Thermal and hydrodynamic performance of micro channel is investigated using different parameters.

Concentric circular micro channel heat exchanger with slip flow has more effectiveness than the no-slip flow. As Reynolds number increases effectiveness of micro channel decreases. The trend of effectiveness difference between slip and no-slip is independent of Reynolds number, channel material and type of flow (counter and parallel flow). The micro channel heat exchanger with aluminium material has more effectiveness than the copper for counter flow.

Pressure drop [2]rises with increment in Reynolds number [1].Total drop in pressure of micro channel unit increases with increasing Reynolds number. With higher values of Knudsen number pressure drop rises at given Reynolds number.

The slip velocity at near the wall is increasing and velocity at core is decreasing with increased value of Knudsen number [1]. Rate of heat transfer is also increasing as Reynolds number increases. Overall heat transfer coefficient [2] is varying throughout the axial distance. It has highest value at the inlet.

The Nusselt number is increasing with higher values of Knudsen number. It happens due to the large velocity slip and maximum energy exchange. 
The heat transfer coefficient [2] and Nusselt number are decreasing until the fully developed flow achieved. It has constant value near of fully developed flow.

The performance index decreases when Reynolds number increases. Performance index represents the overall performance of micro channel heat exchanger [2].

\section{REFERENCE}

1. Frank M. White, Fluid Mechanics

2. Yunus A. Cengel, Afshin J. Ghajar, Heat and Mass Transfer

3. Tuckerman, D.B. and Pease, R.F., 1981, "High performance heat sinking for VLSI", IEEE electron device letter 2, 126-129

4. Harpole, G.M. and Eninger, J.E., 1991, "Micro-channel Heat Exchanger Optimization", Proceedings of the Seventh IEEE Semi Therm Symposium, 59-63

5. Copeland, D., Behnia, M. and Nakayama W., 1996, "Manifold Microchannel Heat Sinks: Isothermal Analysis", Proceedings of ITHERM V, 251-257

6. Bau, H.H., 1998, "Optimization of Conduits' Shape in Micro Heat Exchangers", International Journal of Heat and Mass Transfer, 41, 2717-2723

7. Vafai, K and Zhu, L, 1999, "Analysis of Two-Layered Micro-Channel Heat Sink Concept in Electronic Cooling”, International Journal of Heat and Mass Transfer, 12, 2287-97

8. Serizawa, A., Feng, Z. and Kawara, Z., 2002, "Two-Phase Flow in Micro-Channels", Exp.Therm. Fluid Sci., 26, 703-714

9. Stephan, P., 2002, "Microscale Evaporative Heat Transfer: Modeling and Experimental Validation", 12th Heat Transfer Conference, Grenoble, France.

10. Kandlikar, S.G. and Grande, W.J., 2003, "Evolution of Microchannel Flow Passages Thermo hydraulic Performance and Fabrication Technology", Heat Transfer Eng. 24, 3-17

11. Choi, S. B., Barron, R. F., and Warrington, R. O., 1991, "Fluid Flow and Heat Transfer in Microtubes", Micromechanical Sensors, Actuators, and Systems, 32, ASME, 123-134

12. Pfahler, J., Harley, J., Bau, H., and Zemel, J. N., 1990, "Gas and Liquid Transport in Small Channels", Micromechanical Sensors, Actuators, and Systems, 19, ASME, 149-157.

13. Harley, J., Huang, Y., Bau, H., and Zemel, J. N., 1995, "Gas Flows in Micro-Channels", J. Fluid Mech., 284, 257-274

14. Palm, B., 2000, "Heat transfer in microchannel", Proceedings of Heat Transfer and Transport Phenomena in Microchannel, Begell House Inc., Banff, Canada, 54-64

15. Araki, T., Kim, M. S., Hiroshi, I., and Suzuki, K., 2000, "An Experimental Investigation of Gaseous Flow Characteristics in Microchannels", Proceedings of International Conference on Heat Transfer and Transport Phenomena in Microscale, G. P. Celata, ed., Begell House, New York, 155-161

16. Larrode, F. E., Housiadas, C., and Drossinos, Y., 2000, "Slip Flow Heat Transfer in Circular Tubes", Int. J. Heat Mass Transfer, 43, 2669-2680

17. Duan, J., and Muzychka, Y. S., 2008 "Slip Flow Heat Transfer in Annular Microchannels with Constant Heat Flux", ASME J. Heat Transfer, 130 / 092401-7

18. Peng, X.F. and Petrson, G.P., 1996, "Convective heat transfer and flow friction for water flow in microchannel structures", Int. J. Heat Mass Transfer, 39, 2599-2608

19. Yu, S. P., and Ameel, T. A., 2001, "Slip Flow Heat Transfer in Rectangular Microchannels", Int. J. Heat Mass Transfer, 44, 42254234

20. Yu, S. P., and Ameel, T. A., 2002, "Slip Flow Convection in Isoflux Rectangular Microchannels," ASME J. Heat Transfer, 124, 346-355

21. Al-bakhit, H. and Fakheri, A., 2005, "A Hybrid Approach for Full Numerical Simulation of Heat Exchangers", Proceedings of ASME Heat Transfer Summer Conference, San Francisco, USA

22. Khan, W.A. and Yovanovich, M.M., 2007, "Analytical Modeling of Fluid Flow and Heat Transfer in Micro/Nano-Channel Heat Sinks", ASME, IPACK

23. Al-Nimr, M.A., Maqableh, M., Khadrawi, A.F. and Ammourah, S.A., 2009, "Fully Developed Thermal Behaviors for Parallel Flow Microchannel Heat Exchanger". International Communications in Heat and Mass Transfer, 36, 385-390

24. Rachkovskij, D.A., Kussul, E.M. and Talayev, S.A., 1998, "Heat Exchange in Short Microtubes and Micro Heat Exchangers with Low
Hydraulic Losses", Microsystems Technologies, 4, Springer, 151158

25. Brandner, J.J., Anurjew, E., Buhn, L., Hansjosten, E., Henning, T., Schygulla, U., Wenka, A. and Schubert, K., 2006, "Concept and realization of microstructure heat

26. Foli, K., Okaba, T., Olhofer, M., Jon, Y. and Sendhoff, B., 2006 "Optimization of Micro Heat Exchanger: CFD, Analytical Approach and Multi-Objective Evolutionary Algorithms", Int. J. Heat Mass Transfer, 49, 1090-1099

27. Ahmed, M. S., Ahmed, K. M., Mushtaq, I. H., 2011, "Numerical Investigation of Counter Flow Micro channel Heat Exchanger with Slip Flow Heat Transfer", International Journal of Thermal Sciences, $50,2132-2140$ 